\title{
The Cost-Effectiveness of Ibrutinib in Treatment of Relapsed or Refractory Chronic Lymphocytic Leukemia
}

\author{
Sorensen SV ${ }^{1 *}$, Peng $\mathbf{S}^{1}$, Dorman $\mathrm{E}^{1}$, Cote $\mathrm{S}^{2}$, Tambour $\mathbf{M}^{3}$, Pan $\mathrm{F}^{1}$ and Sengupta $\mathbf{N}^{4}$ \\ ${ }^{1}$ Modeling \& Simulation, Evidera, Bethesda, Maryland, USA \\ ${ }^{2}$ Health Market Access and Reimbursement, High Wycombe, UK \\ ${ }^{3}$ Health Economics, Market Access and Reimbursement, Janssen, Solna, Sweden \\ ${ }^{4}$ Janssen Global Market Access, Oncology, Raritan, New Jersey, USA
}

\begin{abstract}
Purpose: Treatment options for patients with previously-treated Chronic Lymphocytic Leukemia (CLL) are limited; no standard of care exists. In the Phase III RESONATE trial, oral, once-a-day, first-in-class covalent Bruton's tyrosine kinase inhibitor ibrutinib was associated with improved Progression-Free Survival (PFS) (Hazard Ratio (HR) 0.106 , $95 \%$ Confidence Interval (CI) 0.07-0.15) and Overall Survival (OS) compared with ofatumumab (crossover-adjusted HR $0.37,95 \% \mathrm{Cl} 0.22-0.62$ ). The current study evaluated the cost-effectiveness of ibrutinib compared to commonly-used therapies for Relapsed or Refractory (R/R) CLL.
\end{abstract}

Patients and methods: A health state model simulated a cohort of R/R CLL patients receiving ibrutinib, ofatumumab, Idelalisib+Ofatumumab (IO), or Physician's Choice (PC) (a mixed bag of treatments) until death or disease progression, at which point they received subsequent treatment or best supportive care. PFS and OS were extrapolated based on data from RESONATE (ibrutinib and ofatumumab) and from indirect treatment comparisons. The analysis was conducted over a 30-year time horizon from a Swedish healthcare payer perspective. Health outcomes and costs were discounted per Swedish guidelines. Costs, Life Years (LYs), Quality-Adjusted LYs (QALYs), and incremental costs per QALYs were evaluated.

Results: Treatment with ibrutinib resulted in increased LYs and QALYs (6.44 and 4.69) compared to ofatumumab (2.79 and 1.94), IO (3.65 and 2.64), and PC (1.95 and 1.34). Ibrutinib was also associated with higher total costs (2,384,966 SEK) compared to ofatumumab (883,489 SEK), IO (1,242,742 SEK), and PC (503,370 SEK), largely due to ibrutinib's longer PFS. Incremental costs per QALYs gained comparing ibrutinib to ofatumumab, IO, and PC were 546,904 SEK, 556,976 SEK, and 562,450 SEK, respectively. Model results are most sensitive to the PFS projection method, discount rates, and time horizon.

Conclusions: Results demonstrate that ibrutinib is cost-effective and greatly improves long-term health outcomes over current treatments in this hard-to-treat population with very high unmet need.

Keywords: Ibrutinib; Cost-effectiveness; Previously treated; Relapsed or Refractory CLL; Idelalisib

\section{Introduction}

Chronic Lymphocytic Leukemia (CLL) is a rare, lymphoproliferative B-cell malignancy characterized by the progressive expansion of monoclonal B lymphocytes [1,2]. In Europe, the incidence of CLL is estimated at 4.9 cases per 100,000 per year [3-9], qualifying as an orphan disease [10]. The disease is more common in men than in women and incidence increases with age [3].

Some patients respond well to initial treatment for CLL, but the majority of patients eventually relapse and require subsequent treatment. There is no standard of care for patients with Relapsed or Refractory (R/R) CLL and second-line treatment tends to result in shorter durations of remission [11]. Chemotherapy, which is commonly prescribed, is associated with cumulative toxicity, genomic instability, secondary malignancies, and resistance to subsequent lines of therapy, leading to reduced life expectancy [12-14].

The clinical sequelae of CLL can have substantial negative impacts on patients' quality of life and day-to-day activities as a result of disease-related symptoms, treatment-related Adverse Events (AEs); and the psychological, socioeconomic, and functional effects of living with the disease. The economic burden of CLL has been estimated to be $€ 201.1$ million per year in Germany [15] and average costs of secondline treatment in the US has been estimated to be $\$ 18,506$ per patient per month [16].
Ibrutinib is a first-in-class, orally administered treatment for $\mathrm{R} / \mathrm{R}$ CLL that has been approved for previously treated CLL and treatmentnaive CLL in the presence of del 17p or TP53 mutations in patients unsuitable for chemo immunotherapy in both the US and Europe. Evidence based on a median of 16-months follow-up from the Phase III RESONATE trial demonstrated ibrutinib's high response rates (Overall Response Rate (ORR) $=90.5 \%$ ) and unprecedented PFS (median not reached, $91.8 \%$ in PFS at 16 months) and OS outcomes (median not reached, $82.1 \%$ still alive at 16 months), compared to ofatumumab $(\mathrm{ORR}=25 \%$, median $\mathrm{PFS}=8.1$ months $)$. Differences in outcomes between ibrutinib vs. ofatumumab were significant (ORR $\mathrm{p}<0.0001$, PFS HR 0.016, 95\% confidence interval 0.01-0.15) [17].

The objective of this study was to assess ibrutinib's cost-effectiveness for treatment of R/R CLL vs. treatments commonly used in clinical practice from the perspective of Swedish healthcare payers.

*Corresponding author: Sorensen SV, Modeling \& Simulation, Evidera, 7101 Wisconsin Ave \#1400, Bethesda, Maryland 20814, USA, Tel: +1 3016647269 Fax: +1 301654 9864; E-mail: Sonja.sorensen@evidera.com

Received September 20, 2016; Accepted October 28, 2016; Published November 07, 2016

Citation: Sorensen SV, Peng S, Dorman E, Cote S, Tambour M, et al. (2016) The Cost-Effectiveness of Ibrutinib in Treatment of Relapsed or Refractory Chronic Lymphocytic Leukemia. Health Econ Outcome Res Open Access 2: 121. doi: 10.4172/2471-268x/1000121

Copyright: (c) 2016 Sorensen SV, et al. This is an open-access article distributed under the terms of the Creative Commons Attribution License, which permits unrestricted use, distribution, and reproduction in any medium, provided the original author and source are credited. 
Citation: Sorensen SV, Peng S, Dorman E, Cote S, Tambour M, et al. (2016) The Cost-Effectiveness of Ibrutinib in Treatment of Relapsed or Refractory Chronic Lymphocytic Leukemia. Health Econ Outcome Res Open Access 2: 121. doi: 10.4172/2471-268x/1000121

Page 2 of 9

\section{Methods}

A simulation model was developed in accordance with international best practices [18] to compare cost-effectiveness outcomes for patients with $\mathrm{R} / \mathrm{R}$ CLL treated with ibrutinib, ofatumumab, Idelalisib+Ofatumumab (IO), or other frequently used treatments (represented by the "Physician's Choice" (PC) arm). The analysis takes the perspective of the Swedish healthcare payer.

\section{Model Structure}

The model (Figure 1) adopted the three health-state approach common in oncology indications (PFS, Post-Progression Survival (PPS), and death). Routine follow-up costs for patients in PFS were assigned based on response to treatment, informed by time to response data from clinical trials. A proportion of patients were assigned to a subsequent line of treatment during the PPS health state. Patients who did not receive subsequent treatment or who progressed on subsequent treatment were modeled to receive Best Supportive Care (BSC), a form of symptom management.

Patients transition between health states in the model based on a survival partition approach, whereby the area under the PFS or OS curve at a given time is used to determine the fraction of patients who remain in that state at that time. Costs and health effects (i.e., utility values) were assigned to each health state. A four-week model cycle was used. As the model progressed cycle-by-cycle for the duration of the time horizon, cost and utility data were summed per treatment arm, allowing for the calculation of incremental costs and effectiveness per comparator.

The modeling approach was developed to capture key aspects of the R/R CLL disease and treatment pathway and was informed by review of previous modeling studies in this disease area [19-21]. The three health state structure was found to be the most commonly used and well-accepted approach for modeling CLL based on submissions to multiple health technology assessment agencies, including the National Institute for Health and Care Excellence (NICE), the panCanadian Oncology Drug Review (pCODR), the Scottish Medicines Consortium (SMC), and Zorginstituut Nederland. Stratification of the PFS health state by response status was included as published modeling studies indicated and clinical expert opinion confirmed that the costs associated with monitoring and treating disease, and the health utilities experienced by patients, were correlated with response to treatment $[22,23]$. Subsequent-line treatment was included in the model to maintain face validity, as real-world practice and clinical trials indicate that patients tend to receive multiple lines of treatment across their lifetimes. However, it was assumed that subsequent treatment does not affect the OS captured in the trial. This assumption was based on the fact that subsequent lines of therapy have diminishing returns for prolonging OS and because there were no data to inform an alternative assumption for post-progression OS.

The model was reviewed by external experts, who verified that the model was based on an appropriate disease pathway and that clinical assumptions and data sources used were reasonable. Additionally, model programming was validated by a third party to ensure accuracy. Statistical fittings for PFS and OS were validated by comparing of observed PFS and OS Kaplan-Meier (KM) data for ibrutinib to the curves derived from the predictions. The PFS and OS extrapolated data matched well against the KM curves from the trial.

\section{Population}

Baseline characteristics of the model population were based on the RESONATE trial population, with a median age at baseline of 66.5 years, and patients had failed at least one prior treatment. The patient starting age was used to assign the age-stratified general population mortality that served as the minimum all-cause mortality boundary.

\section{Comparators}

There is no standard of care in R/R CLL and clinical trial data to inform comparative efficacy between treatment options is very limited. Three comparators-ofatumumab, IO, and PC, which reflects a proxy for clinical practice-were included in the model based on 1) their relevance to current clinical practice; and 2) the quality of available data to inform clinical inputs in the model.

RESONATE compared ibrutinib vs. ofatumumab, providing direct head-to-head evidence of the comparative efficacy of these two treatments. Ofatumumab is a CD20 antibody used in numerous geographies for treatment of R/R CLL with demonstrated activity in the indication. An Indirect Treatment Comparison (ITC) using the Bucher methodology [24], a rigorous, well-validated methodology for establishing relative treatment effects, based on data from RESONATE (comparing ofatumumab and ibrutinib) and published results from two other RCTs: Phase III, open-label Study 119 comparing IO vs. Ofatumumab [25], and Phase III, open-label, trial OMB114242 comparing ofatumumab with PC [26]. The Committee for Medicinal Products for Human Use has recommended idelalisib "in combination with an anti-CD20 monoclonal antibody (rituximab or ofatumumab) for the treatment of adult patients with CLL who have received at least one prior therapy [27]”. In study OMB114242, PC was comprised of a mixed bag of the most frequently-used therapies for treatment of $R / R$ CLL and represented the best available treatment options as determined by the treating physician, which included a mix of therapies similar to that captured in a recent retrospective study of R/R CLL patients in Sweden [28]. The composition of PC (for costing purposes) is detailed in Table 1.

A key assumption of a Bucher ITC is that the populations of the trials being compared are similar. RESONATE and Study 119 enrolled very similar populations. Study OMB114242 enrolled patients who were refractory to treatment and had bulky disease, which differed from the RESONATE eligibility criteria. Accordingly, the RESONATE population from which ITC inputs were calculated was restricted to reflect the eligibility criteria from OMB11424. Full details of the methods and results of the ITC have been previously published [29].

\section{Model Inputs}

All model inputs are listed in Table 1; costs per model cycle are presented in Table 2 .

Clinical inputs: Parametric survival analysis was used to project OS and PFS curves beyond the end of the clinical trial data. Individual patient-level data from RESONATE [30], were analyzed and fitted with various commonly-used distributions. Based on goodness-of-fit criteria, visual comparison, and clinical plausibility, a Weibull distribution was selected for both OS and PFS. Curves were fit separately for ibrutinib and ofatumumab survival data. At a median of 16 months follow-up, $59 \%$ of ofatumumab patients had crossed over to the ibrutinib arm of RESONATE, resulting in contamination of ofatumumab survival estimates and making it necessary to adjust for the impact of crossover. A rank-preserving structural failure time (RPSFT) model (which is well suited for situations where rate of crossover is high $[31,32]$ ) was used to adjust for crossover. PFS and OS for the PC and IO arms were calculated by applying the hazard ratios derived from ITCs to the ibrutinib PFS and OS curves as a reference. The resulting PFS and OS curves are shown in Figure 2. 
Citation: Sorensen SV, Peng S, Dorman E, Cote S, Tambour M, et al. (2016) The Cost-Effectiveness of Ibrutinib in Treatment of Relapsed or Refractory Chronic Lymphocytic Leukemia. Health Econ Outcome Res Open Access 2: 121. doi: 10.4172/2471-268x/1000121

Page 3 of 9

\begin{tabular}{|c|c|c|c|c|}
\hline Clinical & Ofatumumab & $\begin{array}{l}\text { Ibrutinib vs. } \\
\text { ofatumumab }\end{array}$ & $\begin{array}{l}\text { Ibrutinib vs. idelalisib } \\
\text { ofatumumab }\end{array}$ & Ibrutinib vs. physician's choice \\
\hline $\begin{array}{l}\text { PFS HRs (ibrutinib vs. } \\
\text { comparator) }(95 \% \mathrm{CI} \text { ) } \\
\text { (Source) }\end{array}$ & Reference arm & $\begin{array}{l}\text { Direct trial projection of } \\
16-\text { month data }\end{array}$ & $\begin{array}{c}0.41(0.25-0.66) \\
\text { (ITC vs. study 119) }\end{array}$ & $\begin{array}{c}0.06(0.04-0.11) \\
(\text { ITC vs. OMB114242) }\end{array}$ \\
\hline $\begin{array}{l}\text { OS HRs (ibrutinib vs. } \\
\text { comparator) }(95 \% \mathrm{Cl}) \\
\text { (Source) }\end{array}$ & Reference arm & $\begin{array}{c}0.37(0.21-0.65) \\
\text { (Brown, 2014, adjusted for } \\
\text { crossover) }\end{array}$ & $\begin{array}{c}0.50(0.23-1.08) \\
\text { (ITC vs. study 119) }\end{array}$ & $\begin{array}{c}0.25(0.12-0.54) \\
\text { (ITC vs. OMB114242) }\end{array}$ \\
\hline $\begin{array}{c}\text { Overall response Rate } \\
\text { odds ratio (ibrutinib vs. } \\
\text { comparator) }(95 \% \mathrm{Cl}) \\
\text { (Source) }\end{array}$ & Reference arm & $\begin{array}{l}27.79(15.67-49.30) \\
\quad(\text { Brown, 2014) }\end{array}$ & $\begin{array}{l}2.06(0.87-4.86) \\
\text { (ITC vs. study } 119)\end{array}$ & $\begin{array}{l}45.85(17.67-119.00) \\
\text { (ITC vs. OMB114242) }\end{array}$ \\
\hline $\begin{array}{l}\text { Adverse event s } \\
\quad \text { (Source) }\end{array}$ & $\begin{array}{c}\text { lbrutinib } \\
\text { (RESONATE) }\end{array}$ & $\begin{array}{l}\text { Ofatumumab } \\
\text { (RESONATE) }\end{array}$ & $\begin{array}{c}\text { Idelalisib } \\
\text { ofatumumab } \\
\text { (Study 119) }\end{array}$ & $\begin{array}{l}\text { Physician's choice* } \\
\text { (OMB114242) }\end{array}$ \\
\hline Anemia & $5.6 \%$ & $7.3 \%$ & $12.0 \%$ & $9.3 \%$ \\
\hline Diarrhea & $4.6 \%$ & $1.6 \%$ & $20.2 \%$ & NR \\
\hline Pneumonia & $10.8 \%$ & $5.8 \%$ & $12.7 \%$ & $18.6 \%$ \\
\hline Hypertension & $6.2 \%$ & $0.5 \%$ & NR & NR \\
\hline Neutropenia & $18.5 \%$ & $13.6 \%$ & $34.1 \%$ & $9.3 \%$ \\
\hline Thrombocytopenia & $5.6 \%$ & $4.2 \%$ & $13.3 \%$ & NR \\
\hline Sepsis & $1.5 \%$ & $1.0 \%$ & NR & $14.0 \%$ \\
\hline Utility & \multicolumn{2}{|c|}{ Value (SE) } & \multicolumn{2}{|r|}{ Source } \\
\hline Baseline utility & \multicolumn{2}{|c|}{$0.76(0.012)$} & \multicolumn{2}{|r|}{ Derived from RESONATE EQ-5D data } \\
\hline $\begin{array}{l}\text { Utility while progression } \\
\text { free }\end{array}$ & \multicolumn{2}{|c|}{$0.80(0.005)$} & \multicolumn{2}{|r|}{ Derived from RESONATE EQ-5D data } \\
\hline $\begin{array}{l}\text { Utility decrement due to } \\
\text { disease progression }\end{array}$ & \multicolumn{2}{|c|}{$-0.10(0.010)$} & \multicolumn{2}{|r|}{ Derived from Beusterien et al. 2010} \\
\hline $\begin{array}{c}\text { Range of utility decrements } \\
\text { due to AEs }\end{array}$ & \multicolumn{2}{|c|}{0.09 to 0.20} & \multicolumn{2}{|c|}{ Dervied from Beusterien et al., 2010 and Tolley et al., 2013} \\
\hline $\begin{array}{l}\text { Dosing and treatment } \\
\text { duration }\end{array}$ & Ibrutinib & Ofatumumab & $\begin{array}{c}\text { Idelalisib } \\
\text { ofatumumab }\end{array}$ & Physician's choice ${ }^{\star *}$ \\
\hline $\begin{array}{l}\text { Dosing regimen } \\
\text { (Source) }\end{array}$ & $\begin{array}{c}420 \mathrm{mg} / \text { day for a } \\
\text { 28-day cycle until } \\
\text { disease progression, } \\
\text { unacceptable toxicity } \\
\text { [46] }\end{array}$ & $\begin{array}{l}300 \mathrm{mg} \text { on day } 1 \text { of week } \\
1,2000 \mathrm{mg} \text { weekly from } \\
\text { week } 2 \text { to week } 8,2000 \\
\text { mg every } 4 \text { weeks from } \\
\text { week } 12 \text { to week } 24 \text { [47] }\end{array}$ & $\begin{array}{c}\text { Idelalisib: } 150 \mathrm{mg} \\
\text { twice daily } \\
\text { Ofatumumab: } 300 \mathrm{mg} \\
\text { IV week } 1 \text { then } 1 \mathrm{gram} \\
\text { IV weekly for } 7 \text { weeks } \\
\text { and then every } 4 \\
\text { weeks for } 4 \text { cycles [48] }\end{array}$ & 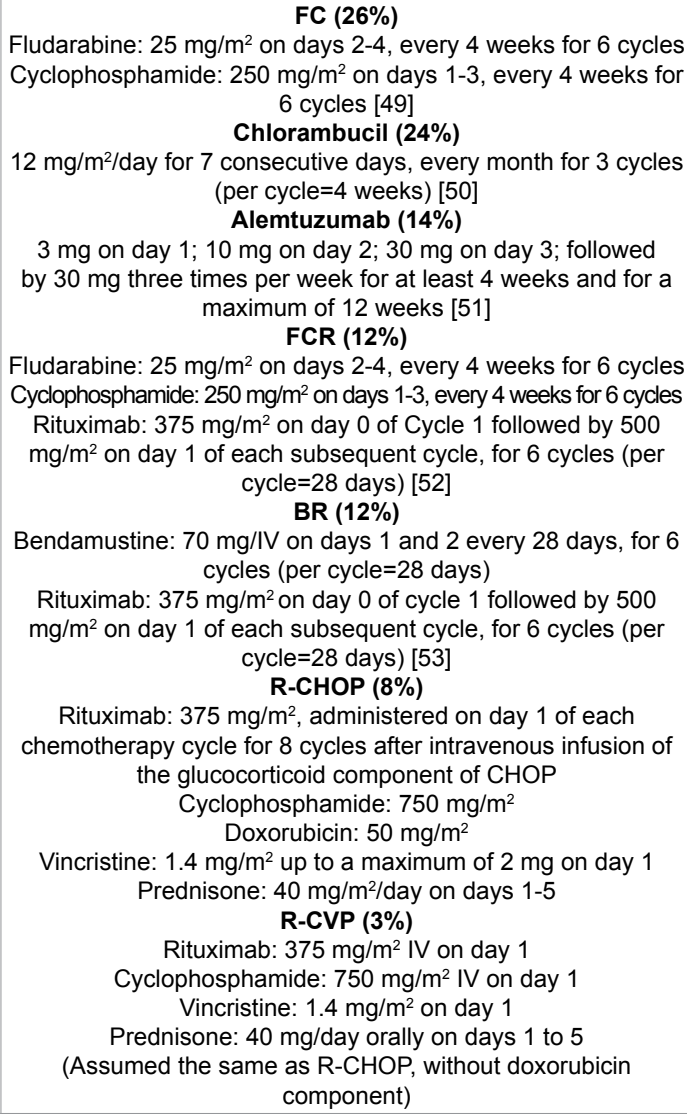 \\
\hline
\end{tabular}


Citation: Sorensen SV, Peng S, Dorman E, Cote S, Tambour M, et al. (2016) The Cost-Effectiveness of Ibrutinib in Treatment of Relapsed or Refractory Chronic Lymphocytic Leukemia. Health Econ Outcome Res Open Access 2: 121. doi: 10.4172/2471-268x/1000121

Page 4 of 9

\begin{tabular}{|c|c|c|c|c|}
\hline $\begin{array}{c}\text { Maximum treatment } \\
\text { duration } \\
\text { (Source: implemented per } \\
\text { SmPC and/or trial upon } \\
\text { which dosing schedule was } \\
\text { based) }\end{array}$ & $\begin{array}{c}\text { Treatment } \\
\text { discontinuation data } \\
\text { (during trial period); } \\
\text { Weibull projection of } \\
\text { PFS beyond study } \\
\text { period }\end{array}$ & 24 weeks & $\begin{array}{l}\text { Idelalisib: Weibull } \\
\text { projection of PFS } \\
\text { (no treatment } \\
\text { discontinuation data } \\
\text { available) } \\
\text { Ofatumumab: } 24 \\
\text { weeks }\end{array}$ & $\begin{array}{l}\text { FC: six four-week cycles } \\
\text { Chlorambucil: three four-week cycles } \\
\text { Alemtuzumab: } 12 \text { weeks } \\
\text { BR: six four-week cycles } \\
\text { FCR: six four-week cycles } \\
\text { R-CHOP: eight three-week cycles } \\
\text { R-CVP: eight three-week cycles }\end{array}$ \\
\hline
\end{tabular}

${ }^{*}$ Assumed to be the same as reported in study OMB114242 [44].

${ }^{* *}$ PC costed as a mixed bag of: FC (26\%), chlorambucil (24\%), alemtuzumab (14\%), FCR (12\%), BR (12\%), R-CHOP (8\%), and RCVP (3\%).

Abbreviations: PFS: Progression-Free Survival; Cl: Confidence Interval; HR: Hazard Ratio; ITC: Indirect Treatment Comparison ; PC: Physician's Choice; IO: Idelalisib+Ofatumumab; OS: Overall Survival; AE: Adverse Event; NR: Not Reported; SE: Standard Error; EQ-5D: EuroQol 5 Dimensions Questionnaire; FC: Fludarabine+Cyclophosphamide; IV: Intravenous; FCR: Fludarabine+Cyclophosphamide+Rituximab ; BR: Bendamustine+Rituximab; R-CHOP: Rituximab+Cyclophospha mide+Doxorubicin+Vincristine+Prednisone; R-CVP: Rituximab+Cyclophosphamide+Vincristine+Prednisone

Table 1: Model inputs.

\begin{tabular}{|c|c|c|c|c|}
\hline Costs per 4 week model cycle & Ibrutinib & Ofatumumab & Idelalisib ofatumumab & Physician's choice \\
\hline Drug Costs & 51,987 SEK & $\begin{array}{l}\text { Cycle } 1120,234 \text { SEK } \\
\text { Cycle } 2 \text { 152,678 SEK } \\
\text { Cycles } 3+38,170 \text { SEK }\end{array}$ & $\begin{array}{l}\text { Cycle } 190,809 \text { SEK } \\
\text { Cycle } 2104,169 \\
\text { Cycle } 3-646,914 \text { SEK } \\
\text { Cycle } 7+27,830\end{array}$ & $\begin{array}{c}\text { Cycle } 1 \text { 15,6150 SEK } \\
\text { Cycle 2-3 13,093 SEK } \\
\text { Cycle } 4 \text { 15,587 SEK } \\
\text { Cycle 5+6 } 13065 \text { SEK }\end{array}$ \\
\hline Administration costs & 0 SEK & $\begin{array}{l}\text { Cycle } 1+2 \text { 21,728 SEK } \\
\text { Cycles } 3+5,432 \text { SEK }\end{array}$ & $\begin{array}{l}\text { Cycle } 1+2 \text { 10,864 SEK } \\
\text { Cycle 3-6 5,432 } \\
\text { Cycle } 7+0 \text { SEK }\end{array}$ & $\begin{array}{c}\text { Cycle } 125,519 \text { SEK } \\
\text { Cycle 2-3 21,740 SEK } \\
\text { Cycle } 4 \text { 15,999 SEK } \\
\text { Cycle 5+6 12,849 SEK }\end{array}$ \\
\hline Adverse events (one-off costs) & 10,667 SEK & 5,981 SEK & 14,061 SEK & 15,935 \\
\hline Costs by health state & \multicolumn{2}{|c|}{ Per 4 week model cycle } & \multicolumn{2}{|c|}{ Description } \\
\hline Stable disease/non-response (SE) & \multicolumn{2}{|c|}{ 2,259 SEK (226 SEK) } & \multirow{3}{*}{\multicolumn{2}{|c|}{$\begin{array}{l}\text { Based on Swedish clinical expert input and treatment guidelines for } \\
\text { the frequency of use of the following resources by response category: } \\
\text { blood tests, hematologist visits, telephone contact with hematologists, } \\
\text { and specialist nurse visits. }\end{array}$}} \\
\hline Complete or partial response (SE) & \multicolumn{2}{|c|}{ 1,156 SEK (156 SEK) } & & \\
\hline $\begin{array}{l}\text { Post-progression on subsequent } \\
\text { treatment (SE) }\end{array}$ & \multicolumn{2}{|c|}{ 6,396 SEK(640 SEK) } & & \\
\hline Best supportive care (SE) & \multicolumn{2}{|c|}{ 9,196 SEK (917 SEK) } & \multicolumn{2}{|c|}{$\begin{array}{l}\text { Based on Swedish clinical expert input and treatment guidelines } \\
\text { for the frequency of use of the following resources: blood tests, } \\
\text { hematologist visits, telephone contact with hematologists, specialist } \\
\text { nurse visits., full blood transfusions, G-CSF, subcutaneous gamma } \\
\text { globulin, platelet transfusions. }\end{array}$} \\
\hline Subsequent line of treatment (drug cost) & \multicolumn{2}{|c|}{$\begin{array}{l}\text { Cycle } 152,390 \text { SEK } \\
\text { Cycle } 2 \text { and } 316,560 \\
\text { Cycles } 433,120\end{array}$} & \multirow{2}{*}{\multicolumn{2}{|c|}{$\begin{array}{c}\text { Subsequent treatment assumed to be rituximab; dosing schedule and } \\
\text { treatment duration based on Furman, } 2014 \text { [54] }\end{array}$}} \\
\hline $\begin{array}{l}\text { Subsequent line of treatment } \\
\text { (administration cost) }\end{array}$ & \multicolumn{2}{|c|}{$\begin{array}{l}\text { Cycle } 154,320 \text { SEK } \\
\text { Cycle } 2 \text { and } 327,160 \\
\text { Cycle } 454,320\end{array}$} & & \\
\hline Terminal care (one-off cost) (SE) & \multicolumn{2}{|c|}{ 61,159 SEK (6,116 SEK) } & \multicolumn{2}{|c|}{$\begin{array}{l}\text { Based on terminal care cost used in Bendamustine TLV Submission } \\
\qquad[55]\end{array}$} \\
\hline
\end{tabular}

Abbreviations: SE: Standard Error; SEK: Swedish Krona; G-CSF: Granulocyte-Colony Stimulating Factor; IO: Idelalisib+ofatumumab; PC: Physician's choice

Table 2: Calculated costs per model cycle.

While extrapolated projections of PFS and OS extrapolated data matched well against the KM curves from the trial, with $91.8 \%$ of ibrutinib patients still in PFS and $82 \%$ still alive at a median of 16 months follow-up in RESONATE, long-term projection of PFS and OS outcomes cannot be well validated by trial data. Accordingly, an alternative parametric fitting for PFS and several alternative approaches toward estimating OS were tested in sensitivity analyses (as discussed in model analyses).

Patients in the model were assumed to continue treatment until the first of death, disease progression, or reaching the maximum treatment duration. Definitions of maximum treatment duration for each therapy are presented in Table 1.

AEs reported in clinical trials as occurring in $\geq 5 \%$ of patients for ibrutinib, ofatumumab, IO, or PC was included. The $5 \%$ cutoff was considered by clinical experts to be sufficient to capture AEs that would impact patients with any consistency and to have validity in real-world settings, where AEs are monitored in a less strict manner compared with a clinical trial setting. While this cutoff may exclude some AEs, cost and quality of life considerations associated with AEs are not model drivers. The $\geq 5 \%$ cutoff is also consistent with the study OMB114242 Österborg et al., a study that reported serious AEs that occurred in $\geq 5 \%$ of the trial population, and is more inclusive than the $\geq 15 \%$ cutoff used in reporting AEs from Study 119 [25].

The probability of receiving a subsequent line of treatment (41.9\%) was based on evidence from RESONATE. Time to progression while on a subsequent line of treatment was assumed equal to the PFS for the rituximab arm of the Furman 2014 trial (Study 116). It was assumed that subsequent treatment does not impact OS captured in the trial, due to the fact that subsequent lines of therapy have diminishing returns for prolonging OS and a lack of data to inform an alternative assumption for post-progression OS.

Utility and cost inputs: Baseline health state utility values were based on an analysis of EQ-5D data from RESONATE. Utility increments due to response to treatment and PFS on subsequent treatment lines and utility decrements due to progression of disease and adverse events were based on three published studies identified in a systematic literature review [33-35]. 
Citation: Sorensen SV, Peng S, Dorman E, Cote S, Tambour M, et al. (2016) The Cost-Effectiveness of Ibrutinib in Treatment of Relapsed or Refractory Chronic Lymphocytic Leukemia. Health Econ Outcome Res Open Access 2: 121. doi: 10.4172/2471-268x/1000121

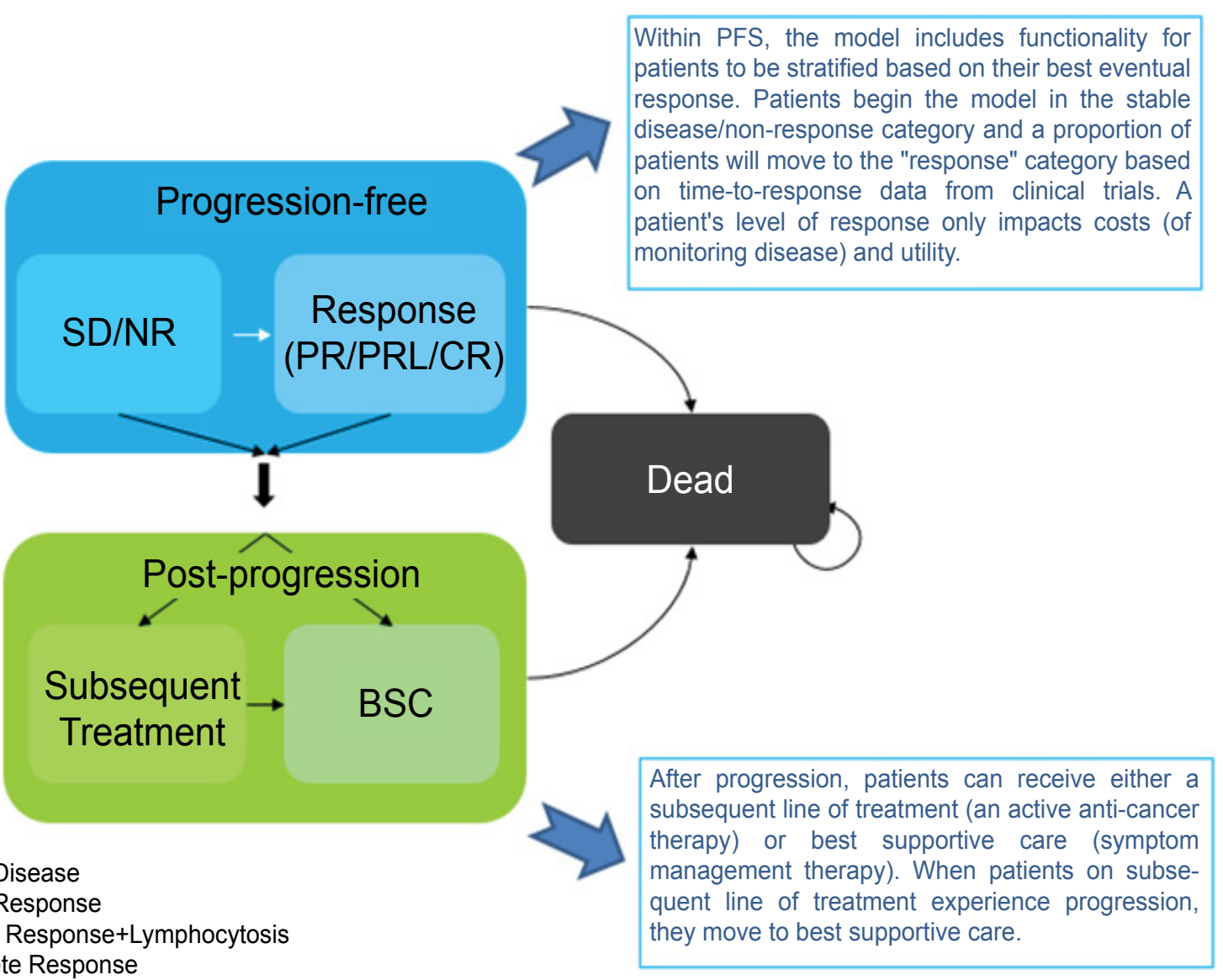

SD: Stable Disease

PR: Partial Response

PRL: Partial Response+Lymphocytosis

CR: Complete Response

NR: No Response

PFS: Progression Free Survival

BSC: Best Supportive Care patients to be stratified based on their best eventual response. Patients begin the model in the stable disease/non-response category and a proportion of patient's level of response only impacts costs (of monitoring disease) and utility.

Figure 1: Model structure.

a)

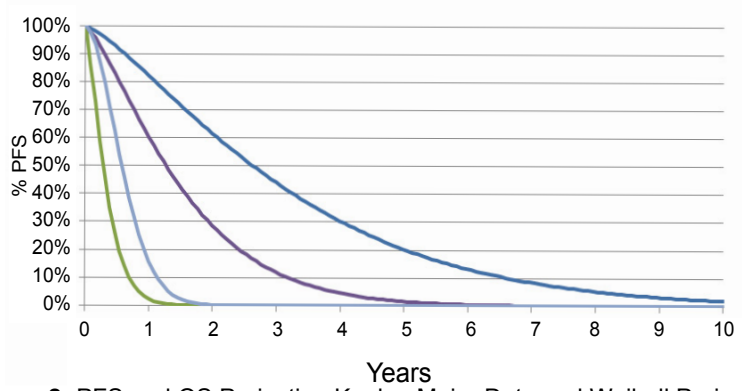

b)

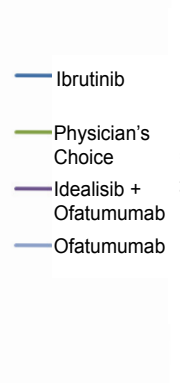

Figure 2: PFS and OS Projection Kaplan Meier Data and Weibull Projection for Ibrutinib, Ofatumumab, Idelalisib+ofatumumab and Physician's choice.

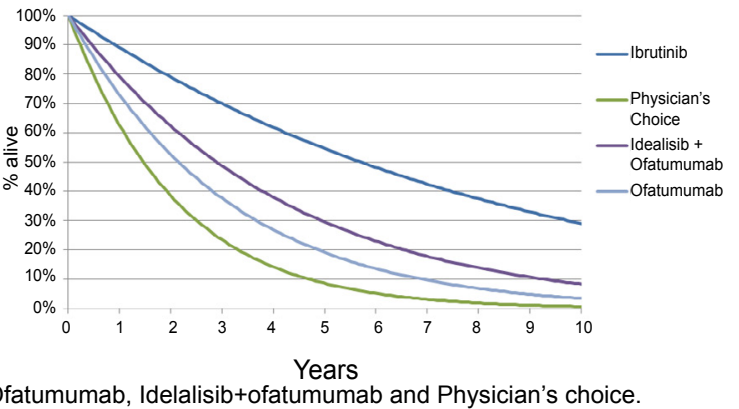

case, meaning that IV drug costs were based on the full cost of the number of vials needed for a given dose, rather than the exact dose required. A sensitivity analysis was considered in which no drug wastage as assumed. Costs of adverse events were accounted for separately for each comparator as a one-time cost (applied at model start, cycle 0) computed by multiplying the rate of the event for that comparator by 
the average cost for that event. Resource use for regular monitoring, BSC and treatment of adverse events were based on Swedish clinical guidelines for CLL and complemented by survey of clinical key opinion leaders in Sweden. The estimated cost of the different resource categories where then obtained by multiplying individual resource items with unit cost data obtained from a large public health care provider in the south of Sweden [36]. The same approach has been used and accepted by the Swedish reimbursement agency in evaluation of ibrutinib [37], as well as other CLL therapies (e.g., ofatumumab [3,38] and obinutuzumab [4]). Moreover, the source for unit cost data in the model for this manuscript was also used in these evaluations by the Swedish reimbursement agency [39]. Costs of subsequent lines of treatment are based on the cost of rituximab, a commonly-used later line therapy.

\section{Model analyses}

The base case analyses evaluated a 30-year time horizon and applied a discount rate of $3.0 \%$ to cost and health benefits. Clinical outcomes were expressed as gains in Life Years (LY) or Quality-Adjusted Life Years (QALYs). Cost-effectiveness was measured in terms of an incremental costs per QALYs gained comparing the additional costs of ibrutinib vs. ofatumumab or PC with ibrutinib's incremental clinical benefit.

A Deterministic Sensitivity Analysis (DSA) was run to explore the impact on results of changes in key parameters. The parameters varied in the sensitivity analysis included time horizon; discount rates; OS and PFS projection approaches; treatment duration; parameters defining subsequent lines of treatment (percent of patients, treatment distribution, PFS); drug costs, wastage, and dose intensity; costs of routine care in each health state; and utility values.

A Probabilistic Sensitivity Analysis (PSA) was also conducted for 1,000 replications, varying all parameters randomly within $95 \%$ confidence intervals (where available) or other clinically plausible ranges.

\section{Results}

Ibrutinib was associated with better clinical outcomes than ofatumumab, IO, and PC, with incremental LYs of 3.65, 2.79, and 4.49, respectively, and incremental QALYs of 2.75, 2.05, and 3.35, respectively. Because of the significant increase in LYs for ibrutinib patients, they were projected to spend a longer time on treatment compared to ofatumumab, IO, or PC patients and thus accrued significantly higher total costs. Incremental costs per QALYs gained were 546,904 SEK vs. ofatumumab, 556,976 SEK vs. IO, and 562,450 SEK vs. PC. This translates to incremental costs per QALYs qained of $€ 58,911$, $€ 59,996$, and $€ 60,586$ vs. ofatumumab, IO, and PC, respectively. Base case model results are shown in Table 3.

Results of the DSA comparing ibrutinib vs. ofatumumab, IO, and PC are presented in Figure 3, respectively and indicate that model results are robust to most plausible variations in assumptions and inputs. Results are most strongly influenced by discount rates for cost and health outcomes, PFS projection approach, and time horizon.

Figure 4 displays Cost-Effectiveness Acceptability Curves (CEACs) estimating the probability of ibrutinib being cost-effective vs. ofatumumab, IO, and PC, respectively. The CEACs show that ibrutinib has a greater than $50 \%$ probability of being cost-effective at WTP thresholds higher than 550,000 SEK per QALY vs. ofatumumab, a greater than $50 \%$ probability of being cost-effective at Willingness-To-
Pay (WTP) thresholds higher than 560,000 SEK per QALY vs. IO and vs. PC. At a threshold of 1,000,000 SEK per QALY, the probability of ibrutinib being cost-effective was $82 \%, 74 \%$, and $88 \%$ vs. ofatumumab, $\mathrm{IO}$, and PC, respectively.

\section{Discussion}

Model results indicated dramatic increases in both LYs and QALYs gained for ibrutinib patients compared to patients treated with ofatumumab, IO, or PC. Ibrutinib was also associated with higher treatment costs, driven by ibrutinib's prolonged PFS and associated time on treatment, but lower subsequent treatment costs. While Sweden does not adhere to an explicit willingness-to-pay threshold, ibrutinib's incremental costs per QALYs gained vs. ofatumumab, IO, and PC are well below willingness to pay thresholds that have been accepted for other severe indications [40].

Model results were relatively stable across a variety of different scenarios, as shown by the results of the DSA. Varying the parametric fitting used to project PFS, cost and health discount rates, time horizon, and the duration of ibrutinib treatment benefit had the greatest impact on model results. Scenarios in which shorter time horizons were used and ibrutinib's benefit was restricted may not fully capture ibrutinib's anticipated benefits, but do allow cost of ibrutinib treatment to accrue in the model. These scenarios, therefore, may not be fair representations of ibrutinib's value for money.

This analysis had a number of strengths. The three-health-state model structure was designed to capture the unique aspects of the disease and treatment pathway in question and to make the best use of clinical trial data. The model structure focused on PFS and OS, which are especially salient outcomes for patients, and simulated how a patient's quality of life decreases following progression. The surrogate endpoint of response was considered as it relates to costs, through the frequency of follow-up care, but as there is little evidence to link response rates with long-term health outcomes, response did not drive health outcomes in the model. The three-health-state structure is highly accepted within oncology and has been considered appropriate in numerous health technology assessments in CLL submitted to agencies such as the SMC [41,42] and NICE [20,21]. Additionally, model inputs used the best available data, including head-to-head trial data for the clinical comparison vs. ofatumumab and ITCs for comparison vs. IO and PC.

The model comparators were chosen for their relevance in treatment of R/R CLL and for the rigor of the data available to inform model parameters. PC has particular relevance as a comparator, given that there is no standard of care in R/R CLL. This arm reflects the best available treatments as selected by physicians. As discussed above, IO has immediate relevance as a treatment for R/R CLL in Europe [27]. Furthermore, the comparison of ibrutinib to IO may have relevance as a proxy for assessing the relative efficacy of ibrutinib vs. Idelalisib+Rituximab (IR) in R/R CLL, which recently received a positive recommendation by NICE. Ofatumumab and rituximab are both anti-CD20 monoclonal antibodies; the assumption of comparable efficacy IO and IR is supported by clinical opinion from an advisory board of UK clinicians. Moreover, in a recent single technology appraisal for IR, NICE accepted the assumption of equivalent efficacy between IO and IR [43].

No other published cost-effectiveness analyses of ibrutinib were identified via a systematic literature review and, therefore, results of the current analysis cannot be directly compared to and validated 
Citation: Sorensen SV, Peng S, Dorman E, Cote S, Tambour M, et al. (2016) The Cost-Effectiveness of Ibrutinib in Treatment of Relapsed or Refractory Chronic Lymphocytic Leukemia. Health Econ Outcome Res Open Access 2: 121. doi: 10.4172/2471-268x/1000121

Page 7 of 9

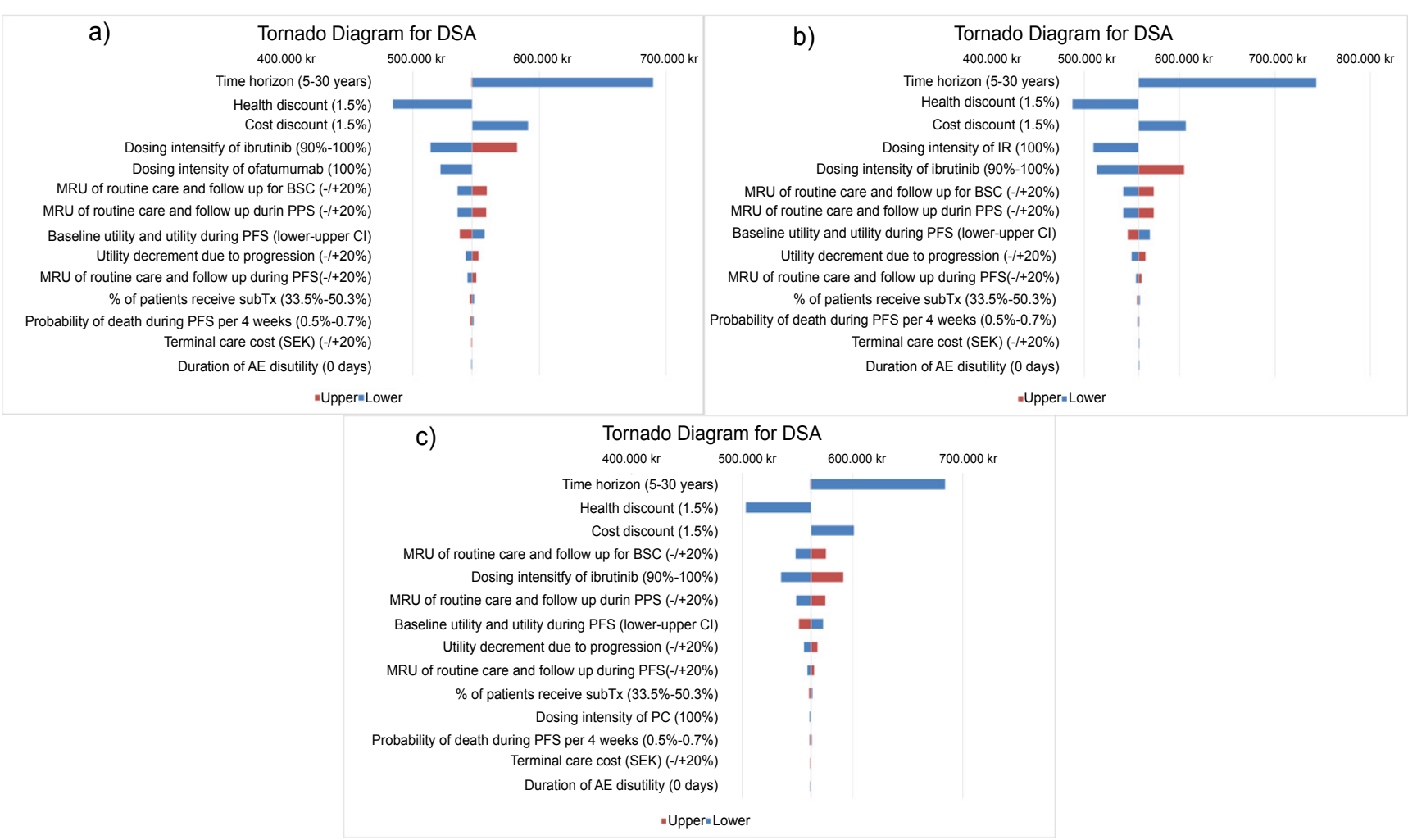

Figure 3: Tornado Diagram of (a) ibrutinib vs. ofatumumab, (b) ibrutinib vs. Idelalisib+ofatumumab, (c) ibrutinib vs. Physician's choice.

\begin{tabular}{|c|c|c|c|c|}
\hline Base Case Results & Ibrutinib & Ofatumumab & Idelalisib ofatumumab & Physician's choice \\
\hline Total costs & $2,384,966$ & 883,489 & $1,242,742$ & 503,370 \\
\hline Total QALYs & 4.69 & 1.94 & 2.64 & 1.34 \\
\hline Total LYs & 6.44 & 2.79 & 3.65 & 1.95 \\
\hline Incremental Costs & - & $1,501,477$ & $1,142,224$ & $1,881,596$ \\
\hline Incremental QALYs & - & 2.75 & 2.05 & 3.35 \\
\hline Incremental LYs & - & 3.65 & 2.79 & 4.49 \\
\hline Cost per QALY (SEK) & - & 546,904 & 556,976 & 562,450 \\
\hline Cost per LY (SEK) & - & 411,390 & 409,181 & 418,638 \\
\hline Cost per QALY (€) & - & 58,911 & 59,996 & 60,586 \\
\hline Cost per LY $(€) \sim$ & - & 44,314 & 44,076 & 45,095 \\
\hline
\end{tabular}

$\sim$ Swedish Krona converted to Euros using an exchange rate of 0.10772 (oanda.com, accessed 1 June, 2016)

Abbreviations: IO: Idelalisib+Ofatumumab; PC: Physician's Choice; QALY: Quality-Adjusted Life Year; LY: Life Year; SEK: Swedish Krona

Table 3: Base case results.

by an external source. However, median PFS estimates generated by the economic model for ofatumumab, PC, and IR were very close to medians reported in the RESONATE [30], OMB114242 [44], and Study 119 trials [25], respectively. Median PFS has not been reached in the RESONATE trial, but projections of ibrutinib's PFS data used in the model align very closely with RESONATE KM data.

The analysis also had limitations that should be acknowledged, largely due to data availability. With $82 \%$ of ibrutinib patients still alive at a median of 16 months in RESONATE, OS outcomes had to be extrapolated in the economic model and long-term predicted outcomes cannot be well validated by trial data. The current study tested uncertainty introduced by implementing a number of alternative approaches to estimating OS outcomes, including alternative parametric fittings and a scenario in which PPS is assumed to be the same for all treatment arms and OS is estimated by summing PFS and
PPS. As expected, results were sensitive to the approach used for OS projection. The base case approach of direct projection from ibrutinib trial data was selected as it makes the best use of trial data and the clinical plausibility of the parametric fitting.

Ibrutinib has the potential to provide additional benefits to patients not captured in this analysis. Ibrutinib is an orally-administrated treatment, which reduces patient burden in comparison to standard infused treatments, which require caregiver support and transportation costs. The potential utility benefit of ibrutinib's oral administration was not captured in this economic analysis. Additionally, long-term results from ibrutinib's Phase II trial (PCYC-1102/1103) indicate that ibrutinib's long-term tolerability profile is very favorable [45]. By prolonging time in PFS, ibrutinib may delay time until the use of more toxic, infusion-based treatments, which can lead to costly and taxing outcomes such as bone marrow depletion. 
Citation: Sorensen SV, Peng S, Dorman E, Cote S, Tambour M, et al. (2016) The Cost-Effectiveness of Ibrutinib in Treatment of Relapsed or Refractory Chronic Lymphocytic Leukemia. Health Econ Outcome Res Open Access 2: 121. doi: 10.4172/2471-268x/1000121

a)

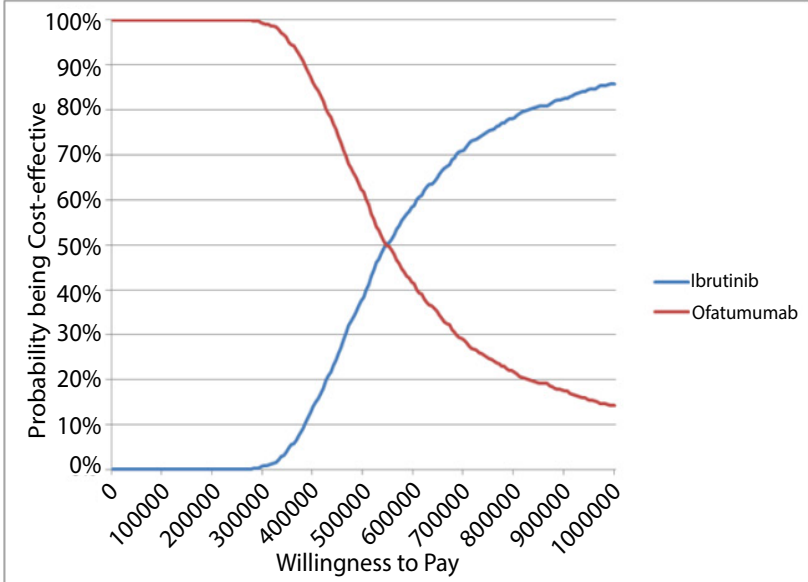

b)

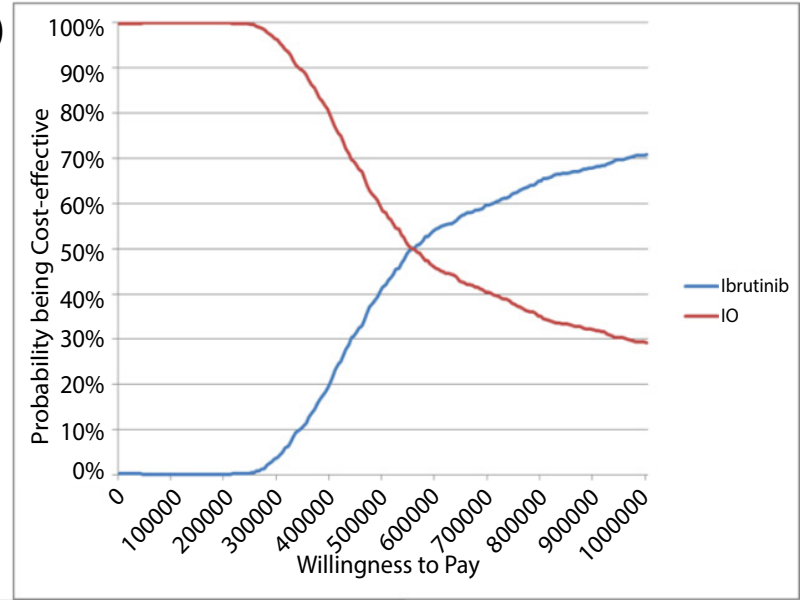

c)

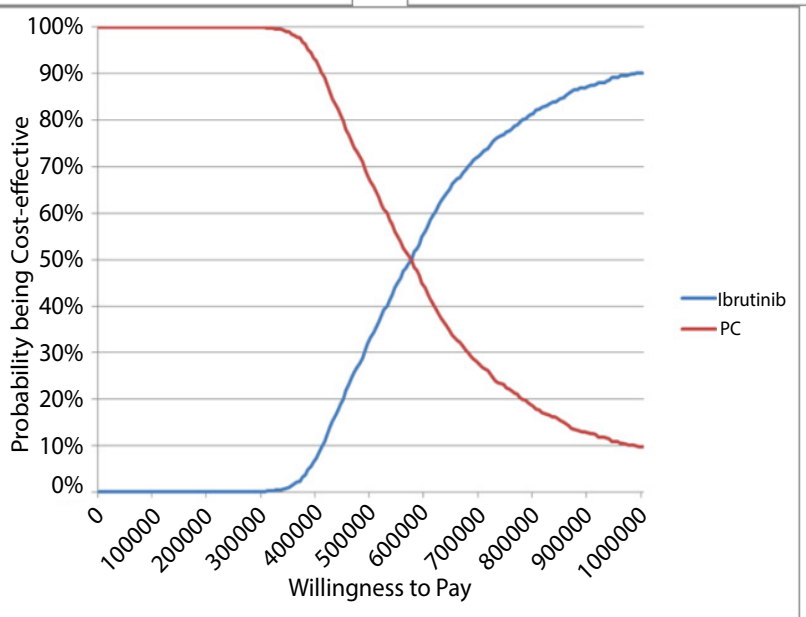

Figure 4: Cost-effectiveness Acceptability Curve of (a) ibrutinib vs. ofatumumab, (b) ibrutinib vs. Idelalisib+Ofatumumab, (c) ibrutinib vs. Physician's Choice.

In summary, ibrutinib offers an unprecedented improvement in long-term health outcomes compared to current treatments for R/R CLL. Incremental costs per QALYs gained were 546,904 SEK vs. ofatumumab, 556,976 SEK vs. IO, and 562,450 SEK vs. PC, which is equivalent to $€ 58,911, € 59,996$, and $€ 60,586$ vs. ofatumumab, IO, and PC, respectively. These results indicate that ibrutinib's health benefits offer significant value to payers seeking to address the high unmet need in this difficult-to-treat population.

\section{Acknowledgement}

Technical writing support was provided by Sarah Brand (Evidera).

\section{Funding}

This work was supported by Johnson \& Johnson.

\section{Disclosure}

Peng, Dorman, Pan, and Sorensen are employees of Evidera, which received consulting fees from Johnson \& Johnson in support of this work. Cote, Tambour, and Sengupta are employees of Johnson \& Johnson.

\section{References}

1. Shanshal M, Haddad RY (2012) Chronic lymphocytic leukemia. Disease a month 58: 153-167.

2. Zenz T, Mertens D, Kuppers R, Dohner H, Stilgenbauer S (2010) pathogenesis to treatment of chronic lymphocytic leukaemia. Nature Reviews: Cancer 10:37-50.

3. Sant M, Allemani C, Tereanu C (2010) Incidence of hematologic malignancies in Europe by morphologic subtype: results of the HAEMACARE project. Blood 11116: $3724-3734$
4. Swedish Association of Hematology (2014) National blood cancer registryCLL.

5. NORDCAN (2015) Cancer stat fact sheets-Finland.

6. NORDCAN (2015) Cancer stat fact sheets-Denmark

7. NORDCAN (2015) Cancer stat fact sheets-Norway.

8. NORDCAN (2015) Cancer stat fact sheets-Iceland.

9. Cancer Research UK (2015) Chronic Lymphocytic Leukaemia.

10. European Medicines Agency (2016) Medicines for rare diseases

11. Stilgenbauer S, Zenz T (2010) Understanding and managing ultra-high-risk chronic lymphocytic leukemia. Hematology: The Education Program of the American Society of Hematology 2010: 481-488.

12. Maddocks KJ, Lin TS (2009) Update in the management of chronic lymphocytic leukemia. J Hematol Oncol 2: 29

13. Hillmen $P$ (2010) Using the biology of chronic lymphocytic leukemia to choose treatment. Hematology. ASH 2011: 104-109.

14. Benjamini $O$, Jain $P$, Trinh $L$ (2015) Second cancers in patients with chronic lymphocytic leukemia who received frontline fludarabine, cyclophosphamide and rituximab therapy: distribution and clinical outcomes. Leuk Lymphoma 56 1643-1650.

15. Blankart CR, Koch T, Linder R, Verheyen F, Schreyogg J, et al. (2013) Cost of illness and economic burden of chronic lymphocytic leukemia. Orphanet $\mathrm{J}$ Rare Dis 8:32.

16. Varker H, Song X, Meyer N (2014) Treatment patterns, mortality, and costs of care in unfit patients (pts) with relapsed chronic lymphocytic leukemia (CLL). American Society of Clinical Oncology Annual Meeting; Chicago, IL, USA. 
Citation: Sorensen SV, Peng S, Dorman E, Cote S, Tambour M, et al. (2016) The Cost-Effectiveness of Ibrutinib in Treatment of Relapsed or Refractory Chronic Lymphocytic Leukemia. Health Econ Outcome Res Open Access 2: 121. doi: 10.4172/2471-268x/1000121

Page 9 of 9

17. Phamacyclics I (2013) Clinical Study Report: A Randomized, Multicenter Open-label, Phase 3 Study of the Bruton's Tyrosine Kinase (BTK) Inhibito Ibrutinib versus Ofatumumab in Patients with Relapsed or Refractory Chronic Lymphocytic Leukemia/Small Lymphocytic Lymphoma, RESONATE ${ }^{\text {TM }} 2013$.

18. Ramsey S, Willke R, Briggs A (2005) Good research practices for costeffectiveness analysis alongside clinical trials: the ISPOR RCT-CEA Task Force report. Value in Health 8: 521-533.

19. National Institute for Health and Care Excellence (2016) Technology appraisal guidance [TA174]: Rituximab for the first-line treatment of chronic lymphocytic leukaemia.

20. National Institute for Health and Care Excellence (2010) Technology appraisa guidance [TA193]: Rituximab for the treatment of relapsed or refractory chronic lymphocytic leukaemia.

21. National Institute for Health and Care Excellence (2016) Technology appraisa guidance [TA202]: Ofatumumab for the treatment of chronic lymphocytic leukaemia refractory to fludarabine and alemtuzumab.

22. GlaxoSmithKline (2010) Ofatumumab (Azerra $\left.{ }^{8}\right)$ for the treatment of chronic lymphocytic leukaemia in patients who are refractory to fludarabine and alemtuzumab. National Institute For Health and Clinical Excellence Single Technology Appraisal (STA)

23. Woods B, Hawkins N, Dunlop W, O'Toole A, Bramham JS (2012) Bendamustine versus chlorambucil for the first-line treatment of chronic lymphocytic leukemia in England and Wales: a cost-utility analysis. Value in Health 15: 759-770.

24. Bucher HC, Guyatt GH, Griffith LE, Walter SD (1997) The results of direct and indirect treatment comparisons in meta-analysis of randomized controlled trials. J Clin Epidemiol 50: 683-691.

25. Jones J, Wach M, Robak T (2015) Poster No. 7023: Results of a Phase 3 Randomized, Controlled Study Evaluating the Efficacy and Safety of Idelalisib (IDELA) in Combination with Ofatumumab (OFA) for Previously Treated Chronic Lymphocytic Leukemi1a (CLL). Paper presented at: 2015 ASCO Annual Meeting; Chicago, IL, USA.

26. Österborg A, Udvary M, Zaritskey A, Andersson P, Grosicki S (2014) Poste No. 4684: Ofatumumab (ofa) vs. physician's choice $(\mathrm{PC})$ of therapy in patients (pts) with bulky fludarabine refractory(BFR) chronice lymphocytic leukemia (CLL): results of the Phase III study OMB114242. Paper presented at: 56th ASH Annual Meeting and Exposition; San Francisco, CA, USA.

\section{European Medicines Agency (2016) Zydelig.}

28. Österborg A, Asklid A, Diels J (2015) Abstract No. 1751: Comparison of Phase 3 Ibrutinib Results Versus Standard of Care in Sweden in Patients with Relapsed/ Refractory (R/R) Chronic Lymphocytic Leukemia (CLL). Paper presented at: 57th ASH Annual Meeting \& Exposition; Orlando, FL, USA.

29. Tam C, Sorensen S, Sengupta N (2015) Poster: Indirect Treatment Comparison of Ibrutinib Versus Physician's Choice for Treatment of Relapsed or Refractory Chronic Lymphocytic Leukemia. Paper presented at: XVI International Workshop on Chronic Lymphocytic Leukaemia; Sydney, Australia.

30. Brown JR, Hillmen P, O'Brien S, Barrientos JC, Reddy N (2014) Poster 3331 Updated Efficacy Including Genetic and Clinical Subgroup Analysis and Overall Safety in the Phase 3 RESONATETM Trial of Ibrutinib Versus Ofatumumab in Previously Treated Chronic Lymphocytic Leukemia/Small Lymphocytic Lymphoma Paper presented at: 56th ASH Annual Meeting and Exposition; San Francisco, CA USA.

31. Ishak KJ, Proskorovsky I, Korytowsky B, Sandin R, Faivre S (2014) Methods for adjusting for bias due to crossover in oncology trials. Pharmacoeconomics 32: $533-546$

32. Latimer NR, Abrams KR (2014) NICE DSU Technical Support Document 16 Adjusting Survival Time Estimates in the Presence of Treatment Switching

33. Beusterien KM, Davies J, Leach M (2010) Population preference values for treatment outcomes in chronic lymphocytic leukaemia: a cross-sectional utility study. Health Qual Life Outcomes 8: 50.

34. Tolley K, Goad C, Yi Y, Maroudas P, Haiderali A (2013) Utility elicitation study in the UK general public for late-stage chronic lymphocytic leukaemia. Eur $J$ Health Econ 14: 749-759.

35. Ferguson J, Tolley K, Gilmour L, Priaulx J (2008) PCN79: Health state preference study mapping the change over the course of the disease process in chronic lymphocytic leukemia. 11th Annual European Congress. Int Soc Pharmacoecon Outcomes Res.
36. https://www.skane.se/sv/Webbplatser/Sodra-regionvardsnamnden/Regionalapriser-och-ersattningar-for-Sodra-sjukvardsregionen/.

37. Swedish Dental and Pharmaceutical Benefits Agency (2015) Reimbursement decision document, Imbruvica.

38. Swedish Dental and Pharmaceutical Benefits Agency (2015) Reimbursement decision, Arzerra.

39. Swedish Dental and Pharmaceutical Benefits Agency (2014) Health technology assessment report, Gazyvaro.

40. Epstein D (2014) HTA in European countries: The use of Comparative Effectiveness Research and Health Technology Assessment in European countries: current situation and prospects for the future.

41. Scottish Medicines Consortium (2009) Rituximab, 100mg and 500mg concentrate for solution for infusion (MabThera) No. (540/09), Roche. Glasgow, Scotland.

42. Scottish Medicines Consortium (2015) Idelalisib 100mg and $150 \mathrm{mg}$ tablets (Zydelig®). SMC No. (1026/15), Gilead Sciences Ltd. Glasgow, Scotland.

43. National Institute for Health and Care Excellence (2016) Technology appraisal guidance [TA359]: Idelalisib for treating chronic lymphocytic leukaemia.

44. Österborg A, Udvardy M, Zaritskey A (2014) Poster No. 4684: Ofatumumab (Ofa) vs. Physician's Choice (PC) of Therapy in Patients (pts) with Bulky Fludarabine Refractory (BFR) Chronic Lymphocytic Leukemia (CLL): Results of the Phase III Study OMB114242. Paper presented at: 56th ASH Annual Meeting Meeting; San Francisco, CA, USA.

45. Byrd JC, Furman RR, Coutre SE (2015) Three-year follow-up of treatmentnaive and previously treated patients with CLL and SLL receiving single-agent ibrutinib.

46. Janssen. Summary of Product Characteristics for Imbruvica® (Ibrutinib). 2015.

47. Novartis Pharmaceuticals UK Ltd. (2015) Summary of Product Characteristics: Arzerra $100 \mathrm{mg} \& 1000 \mathrm{mg}$ concentrate for solution for infusion.

48. Gilead Sciences Limited (2015) Summary of Product Characteristics Zydelig (idelalisib) $100 \mathrm{mg}$

49. Robak T, Dmoszynska A, Solal-Celigny P (2010) Rituximab plus fludarabine and cyclophosphamide prolongs progression-free survival compared with fludarabine and cyclophosphamide alone in previously treated chronic lymphocytic leukemia. Journal of Clinical Oncology 128: 1756-1765.

50. Robak T, Blonski JZ, Kasznicki M, Gora-Tybor J, Dmoszynska A (2005) The effect of subsequent therapies in patients with chronic lymphocytic leukemia previously treated with prednisone and either cladribine or chlorambucil. Haematologica 190: 994-996.

51. Stilgenbauer S, Zenz T, Winkler D (2009) Subcutaneous alemtuzumab in fludarabine-refractory chronic lymphocytic leukemia: clinical results and prognostic marker analyses from the CLL2H study of the German Chronic Lymphocytic Leukemia Study Group. J Clin Oncol 2027: 3994-4001.

52. Badoux XC, Keating MJ, Wang X (2011) Fludarabine, cyclophosphamide and rituximab chemoimmunotherapy is highly effective treatment for relapsed patients with CLL. Blood 17117: 3016-3024.

53. Fischer K, Cramer P, Busch R (2011) Bendamustine combined with rituximab in patients with relapsed and/or refractory chronic lymphocytic leukemia: multicenter phase II trial of the German Chronic Lymphocytic Leukemia Study Group. J Clinl Oncol 1029: 3559-3566.

54. Furman RR, Sharman JP, Coutre SE (2014) Idelalisib and rituximab in relapsed chronic lymphocytic leukemia. N Engl J Med 13370: 997-1007.

55. Swedish Dental and Pharmaceutical Benefits Agency (2015) Reimbursement decision, Bendamustine. 